ISSN: 0213-2079 - ISSN electrónico: 2386-3889

DOI: https://doi.org/10.14201/shhmo2017392153184

\title{
ASPECTOS NAVALES EN EL TRASLADO DE LA CASA DE CONTRATACIÓN
}

\section{Naval Aspects Regarding the Relocation of the House of Trade Headquarters}

\section{Enrique TAPIAS HERRERO}

Capitán de navío de la Armada española en la reserva. Doctor en Historia Correo-e: etapiash@gmail.com

RESUMEN: El traslado de la Casa de Contratación supuso un duro golpe para la economía sevillana; venía a culminar un siglo xvir pleno de desastres naturales y epidemias que habían diezmado a la población. La poderosa influencia política hispalense en la Corte no pudo superar, entre otras cosas, los inconvenientes que presentaba la navegación por el Guadalquivir y la peligrosa barra de Sanlúcar. En el análisis de las múltiples causas que motivaron el traslado, nos centraremos en este trabajo en los aspectos navales que condicionaron la decisión real, tratando de valorar su peso en comparación con otros factores determinantes, como fueron: las diferencias en los baremos fiscales, las posibilidades de fraude que posibilitaba la bahía gaditana, o el poderío económico que habían alcanzado los comerciantes gaditanos. Estudiaremos, igualmente, los protagonismos de diferentes autoridades navales que tuvieron un papel destacado en la decisión final, como los almirantes Pes ${ }^{1}$, Gaztañeta y López Pintado, así como de José Patiño.

Palabras clave: Casa de Contratación; traslado; barra de Sanlúcar; almirantes Pes, Gaztañeta y López Pintado; José Patiño.

1. También conocido como Pez. 
ABSTRACT: The House of Trade relocation to Cadiz impacted heavily on the Sevilian economy after a seventeenth century full of natural disasters and epidemics which reduced the population drastically. The huge politic power of Seville in the Court was not enough to overcome, among other factors, the inconvenience of the navigation through the river and the barrier of Sanlúcar. In the analysis of reasons which motivate the relocation we are giving in this work a special consideration to the naval aspects which were taken into account in the royal decision. At the same time we will try to measure the weight of these aspects comparing to other important factors such as the difference in fiscal taxes between both ports, the possibilities of fraud in the Cadiz bay and the economic power of merchants in this city. Finally, we will assess the role performed by main naval authorities who intervened in the final decision such as: admirals Pes, Gaztañeta, López Pintado and also José Patiño.

Key words: House of Trade; transfer; Sanlucar barrier reef; Admirals Pes, Gaztañeta, López Pintado; José Patiño.

\section{INTRODUCCIÓN}

En la decisión de llevar a cabo el traslado de la Casa de Contratación de Sevilla a Cádiz intervinieron factores de tipo político, económico, marítimo y geoestratégico. En este artículo se pretende investigar de forma destacada el impacto que pudo tener en la decisión real el condicionante naval, en la búsqueda de una mayor eficacia del comercio, y en el manejo y despacho de las flotas que partían para el Nuevo Mundo.

Cuando se selecciona Sevilla como punto focal de las instituciones que se encargarían del comercio con Indias, y por tanto del puerto de salida de las flotas, no había la más mínima duda. Era la mayor ciudad de Castilla, lo que suponía una buena fuente de candidatos para cubrir los cientos, e incluso miles, de puestos necesarios para las diversas tripulaciones, que conformarían las grandes flotas que entonces navegaban regularmente a las Indias. Era un puerto seguro contra posibles ataques de piratas o enemigos, ya que los casi cien kilómetros que lo separaban de la costa permitían una alerta suficiente. No era el mejor puerto de España pero sí uno de los más destacados; de hecho, disponía de una machina (grúa) que por entonces era poco frecuente en los puertos europeos. El Arenal de Sevilla, colindante con la Torre del Oro, había servido durante el siglo anterior para descargar y almacenar las piedras necesarias para la construcción de la catedral que llegaban por el río procedentes del Puerto de Santa María. Esta magnífica

Ediciones Universidad de Salamanca / 뾰 Stud. his., H. ${ }^{a}$ mod., 39, n. 2 (2017), pp. 153-184 
explanada, situada extramuros, y citada hasta la saciedad por nuestros mejores escritores clásicos, sería una magnífica plataforma para el embarque y desembarque de las mercancías y para asentar en ella las diferentes mesas de contratación de las tripulaciones. La ciudad disfrutaba de un importante mercado agrícola y era un centro industrial importante donde destacaba: la seda, artillería, armas y pólvora. Por último, la amplia vega hispalense era una buena fuente de suministros para la alimentación de las tripulaciones y también para el envío a Indias de los frutos de la tierra andaluces, como eran el aceite, vino y aguardiente 2 .

Inicialmente, las embarcaciones que partían eran de escaso tonelaje (normalmente inferiores a doscientas toneladas), lo cual les permitía salir cargadas desde Sevilla sin encontrar problemas durante la navegación fluvial; el paso de la barra rocosa situada frente a Sanlúcar tampoco resultaba un problema. Pero a medida que discurría la Carrera de Indias las embarcaciones incrementaron su tonelaje aumentando su calado, y si a este fenómeno unimos las irregularidades del Guadalquivir en cuanto al caudal de agua, los bancos de arena, así como los numerosos pecios parcialmente hundidos, se puede entender que la mayoría de los navíos, entonces, no pudiesen salir totalmente cargados de Sevilla. Para completar su carga disponían de varios lugares intermedios a lo largo de su cauce, como las Horcadas; este lugar era, hasta las primeras décadas del siglo xviI, uno de los puntos de partida, y también centro de carenas y mantenimiento de navíos. A once kilómetros de Sanlúcar se encontraba otro lugar de reabastecimiento: el Puntal. Como ejemplo de lo apuntado, observamos que en la flota que salió en 1564, de 25 navíos, 13 cargaron en las Horcadas, 6 en el Puntal, y los otros 6 en Sanlúcar. En realidad, ya a finales del siglo xvi los buques de mayor tonelaje salían a media carga de Sevilla. A menudo se utilizaban galeras o embarcaciones menores a remo para salvar los meandros y zonas difíciles donde los vientos no permitían su avance, y de regreso, transportaban hasta Sevilla la carga desembarcada en Bonanza ${ }^{3}$.

Los problemas mencionados se repetían igualmente al retornar las flotas, con el agravante de que no se podía atravesar la doble barra rocosa situada frente a Sanlúcar, si no se daban unas condiciones de marea, viento y visibilidad muy determinadas. En ocasiones, flotas enteras tuvieron que esperar semanas ancladas frente a Chipiona sometidas a la amenaza de piratas, corsarios o enemigos, sin protección alguna de la costa. Otro temor permanente era la llegada de temporales, que hacían garrear sus anclas llevando unos navíos sobre otros, provocando naufragios o daños diversos. Es sintomático que existiese en Sanlúcar junto a un

2. A los que se concedió un tercio de la capacidad de carga de los navíos.

3. Chaunu, P.: Sevilla y América siglos XVI y XVII. Sevilla, 1983.

Ediciones Universidad de Salamanca / 요 Stud. his., H. ${ }^{a}$ mod., 39, n. 2 (2017), pp. 153-184 
gremio de prácticos, necesarios para el paso de la barra, otro de buceadores, ya que los hundimientos en escasas brazas permitían la recuperación de un alto porcentaje de las mercancías. Según Chaunu, el $80 \%$ de los navíos que salían de Sevilla y no llegaban al Nuevo Mundo (hasta mediados del siglo XviI) se habían perdido en el Guadalquivir ${ }^{4}$. Por todos esos motivos, este punto geográfico se convirtió en uno de los mayores cementerios marinos de toda la Carrera de Indias. Otro aspecto significativo es que en muchos seguros de riesgo no se cubrían posibles desastres al pasar la barra ${ }^{5}$. Durante el siglo xviI, con el aumento en tonelaje de los navíos, principalmente de los buques de guerra que actuaban como escoltas y que normalmente superaban en tamaño a los mercantes, los problemas mencionados se agudizaron. Ya en 1588 el duque de Medina Sidonia solicitó permiso a Felipe II para que sus naves capitana y almiranta pudieran salir desde Cádiz, pues tenían dificultades para pasar la barra dado su tonelaje. En realidad, desde finales del siglo xvi parece que los navíos de guerra partían desde la citada capital, y durante la primera mitad del XVII muchos mercantes fueron autorizados a completar allí su carga. Sin embargo, en los retornos la permisividad era menor por temor a la falta de vigilancia de la bahía, que animaba a la desaparición de metales preciosos sin haber pasado por el control fiscal. De hecho, se imponían 2.000 ducados de multa al general o capitán que arribara a Cádiz, como fue el caso del general Antonio de Oquendo, que en 1633 se negó a pasar la barra de Sanlúcar con su nave capitana ${ }^{6}$. Nueve años antes, la Casa de Contratación preveía disponer de buques menores para aligerar la carga de algunos galeones en su retorno, quejándose ya del estado ruin del río.

En contrapartida, la bahía gaditana ofrecía una entrada fácil, un abrigo suficiente para los vientos fuertes, y fondos para todo tipo de tonelajes. En el aspecto defensivo poseía en el fondo de la bahía una gran dársena, a la que se accedía a través de una bocana protegida por los fuertes de Puntales y Matagorda, que mostraron su solidez al rechazar en 1702 las fuerzas del duque de Ormond, que venían embarcadas en la flota anglo-holandesa del almirante Rooke, en su pretensión de incorporar la ciudad de Cádiz para el Archiduque ${ }^{7}$. Durante el siglo xvir, la Corona, recordando la destrucción de la flota mercante por Drake en 1587, y el saqueo de la ciudad por las tropas del conde de Essex en 1596, consideró necesario fortificar

4. Comellas, J. L.: Sevilla, Cádiz y América. El trasiego y el tráfico. Málaga, 1992, p. 28.

5. Bustos Rodríguez, M.: Burguesía de negocios y capitalismo en Cádiz: los Colarte (16501750). Cádiz, 1991, p. 53.

6. Girard, A.: La rivalité commerciale et maritime entre Séville et Cadix. París, 1932, p. 68; Serrano Mangas, F.: Los galeones de la Carrera de Indias 1650-1700. Sevilla, 1985, p. 17.

7. Ruiz de Cortázar, A.: Puerto de Santa María ilustrado y compendio bistorial de sus antigüedades (1764). El Puerto de Santa María, 1997, p. 309; PonCE Cordones, F.: Rota 1702. Un episodio olvidado de la Guerra de Sucesión. Cádiz, 1979.

Ediciones Universidad de Salamanca / 요 Stud. his., H. ${ }^{a}$ mod., 39, n. 2 (2017), pp. 153-184 
la bahía y reforzar las murallas de la ciudad. La burguesía gaditana, cuando alcanzó una excelente posición económica, contribuyó con sus recursos a su rehabilitación y cooperó con el cabildo gaditano hasta dar por finalizada la obra. Historiadores contemporáneos consideraban a la ciudad gaditana como un modelo de plaza fortificada. El amurallamiento representó la obra pública más importante de Cádiz durante el siglo XviII, si bien el proceso fortificador moderno se había iniciado y desarrollado en las dos centurias anteriores. Fue en el setecientos cuando se acabó de configurar la ciudad como plaza fuerte, convirtiéndose en una de las piezas clave del sistema defensivo español. Las sumas que se invirtieron fueron elevadísimas ${ }^{8}$.

En agosto de 1613, a petición de Jerez, el Rey ordenó abrir un canal entre el Guadalquivir y el Guadalete para salvar el grave problema del paso de la barra de Sanlúcar. En 1620, tras la pérdida de doce navíos en el paso de la barra, se reactivó el proyecto 9 . Pero aquí se enfrentaban problemas políticos de altura: el duque de Medina Sidonia, señor de Sanlúcar, se oponía al intento como es fácil de imaginar; por el contrario, el duque de Medinaceli, señor de El Puerto de Santa María, lo veía con muy buenos ojos. El proyecto avanzaba lentamente pero sin pausa, y es en 1717 cuando el almirante Pes solicitó de Patiño, ya Intendente General de Marina, que interviniese para interrumpir los trabajos ${ }^{10}$. En 1626, don Manuel Gaitán de Torres dirigió un memorial al conde-duque de Olivares donde indicaba que en los últimos cinco años se habían perdido en la barra «siete galeones con diez millones de ducados... y un sinnúmero de navíos de flota» por lo que sería lógico «mandar que las flotas y galeones se cargasen en la bahía de Cádiz y volviesen a ella». Asegura Velázquez Gaztelu que al comienzo del reinado de Felipe IV se agudiza la controversia por las dificultades de la barra ${ }^{11}$. Sin embargo, ya Fernando el Católico en 1514 había manifestado con ocasión de la partida de la expedición de Pedrarias Dávila al Darién:

He holgado mucho en saber que las naos han ya bajado a Sanlúcar, pero más quisiera que fueran a partir de Cádiz, porque como sabéis desde allí pueden salir con cualquier tiempo y no desde Sanlúcar ${ }^{12}$.

8. Cano Revora, G. y Torrejón Chaves, J.: «Arbitrios y fortificación: la financiación de las murallas de la ciudad de Cádiz durante el siglo xviII», en Fortea Pérez, J. I. y Cremades Griñán, C. M.: Política y Hacienda en el Antiguo Régime. Actas de la II Reunión Científica de la Asociación Española de Historia Moderna Moratalla (1992), vol. 1. Murcia, 1993, pp. 185-202.

9. Estas cifras no son reconocidas por P. Chaunu.

10. Girard, A.: op. cit., p. 162.

11. Velázquez Gaztelu, J. P.: Estado marítimo de Sanlúcar de Barrameda. Sanlúcar, 1998, p. 268.

12. AGI, Panamá, leg. 233, 1. Real cédula a los oficiales de la Casa de Contratación de 08/02/1514. 
Desde 1630, Sevilla, que veía cada vez con más temor la amenaza gaditana, presionó con fuerza a la Corona para que se trasladara el Juzgado de Indias de Cádiz a Sanlúcar ante los continuos fraudes que se daban en la bahía. En 1661 la Casa de Contratación y en 1664 el Consejo de Indias, insistían en que todos los galeones que pudiesen pasar la barra debían utilizar el puerto de Sanlúcar, sin excepciones. Finalmente, con ocasión de los percances ocurridos en la barra a varios galeones durante 1665 y 1666, la Corona solicitó en este año la opinión de una junta formada por el Consejo de Indias, el Consejo de Castilla y el de Hacienda, que determinaron que se debería suprimir la Aduana y el Juzgado de Indias de Cádiz, y ordenar el regreso de las flotas a Sanlúcar ante la visible decadencia hispalense. Incluso se apuntaba que los frutos que le correspondía embarcar a Cádiz deberían ser llevados a Sanlúcar. Albert Girard comentaba, según Chaunu de forma tardía, que en 1664/1666 había grandes dificultades para los buques de tonelaje mediano, tanto para pasar la barra como para remontar el río hasta Sevilla ${ }^{13}$. Pero poco después, en julio de 1680, la Junta de Guerra de Indias, ante las recientes varadas y naufragios de navíos de gran tamaño sucedidos en la barra, revocó la cédula de 1664 a favor de Sevilla y Sanlúcar, ordenando que en adelante las flotas y galeones deberían entrar en Cádiz, en el saco de Puntales, donde estarían más protegidas. La ciudad gaditana recibió el espaldarazo que le faltaba al ser designada como la cabecera de las flotas en 1680; de todas formas, ya desde 1668 las expediciones navales partían de la capital gaditana.

\section{Evolución del conflicto entre Sevilla y Cádiz}

Recordando el inicio de la pugna entre las dos ciudades se destaca que, ya en 1535, se creó el Juzgado de Indias con el que la Casa de Contratación pretendía fiscalizar los embarques y desembarques de mercancías, no solo en Cádiz sino también en Sanlúcar; con este hecho se reflejaba un crecido interés por el comercio desde la costa atlántica. Desde finales del siglo xvi casi todos los buques de guerra partían de Cádiz, mientras que los mercantes cargaban en algunos casos en la capital gaditana y la mayoría en Sanlúcar. En 1614 se confirmaba esta medida por la Casa de Contratación pero, en cualquier caso, el regreso de los mercantes debía efectuarse en Sanlúcar para una mayor seguridad aduanera ${ }^{14}$. A partir de 1627 estos buques completaban normalmente su carga en Cádiz, y Sevilla que, como se ha dicho, observaba que se le escapaba el control comercial, reaccionó solicitando el

13. Chaunu, P.: Seville et l'Atlantique. París, 1959, t. VIII, p. 294. 196.

14. Veitia Linaje, J.: Norte de la Contratación de las Indias Occidentales. Madrid 1981, p.

Ediciones Universidad de Salamanca / 뾰 Stud. his., H. ${ }^{a}$ mod., 39, n. 2 (2017), pp. 153-184 
traslado del Juzgado de Indias de la capital gaditana a Sanlúcar alegando los fraudes que se daban en la bahía que se encontraba con escasa vigilancia. Estos fraudes se incrementaron a partir de 1635 al entrar en guerra con Holanda y Francia.

En 1600 la población gaditana tenía entre dos mil y cuatro mil habitantes, pero en 1700 el vecindario había crecido hasta alcanzar las cuarenta mil almas. Durante el siglo Xvir se produjo un traslado de comerciantes y mercaderes de Sevilla a Cádiz ante las mayores facilidades del puerto gaditano, no solo en cuanto a la navegación, sino también por las medidas aduaneras e impuestos, mucho más asequibles que los sevillanos ${ }^{15}$. Si a eso se añade la facilidad de realizar contrabando en su bahía, se entiende el desarrollo sorprendente de la ciudad gaditana que, al mismo tiempo, recuperaba la Tabla de Indias y el privilegio del tercio de toneladas ${ }^{16}$. Con el crecimiento del comercio los mercaderes gaditanos alcanzaron el poder político a través del control del cabildo municipal y de la burocracia local ${ }^{17}$; de esta forma, compraron las alcabalas de Cádiz por 370.000 pesos y, a continuación, para aumentar la atracción del comercio sevillano, procedieron a una rebaja de impuestos del diez por ciento sobre la cantidad cobrada en Sevilla. En consecuencia, los comerciantes gaditanos se podían permitir, entre otras cosas, el realizar préstamos o donativos a la Corona que, a su vez, lo agradecía con medidas muy beneficiosas para sus intereses. Y la muestra más palpable de esta relación la tenemos en 1680, cuando Cádiz consiguió la cabecera de las flotas gracias al ofrecimiento a la Corona de 80.250 escudos $^{18}$. El cónsul francés monsieur Catalán comunicaba a su ministro J. B. Colbert en 1670: «el comercio en este puerto de Cádiz es el mayor y más floreciente de Europa» ${ }^{19}$. Según José Luís Comellas, el siglo xvin es «el siglo de oro de Cádiz» y, además, «el siglo mercantil por excelencia» en la historia de España.

Si el siglo xvir fue malo para la economía europea, que sufrió una clara recesión o estancamiento demográfico según las zonas, para España fue mucho peor. Al margen de la expulsión de los moriscos, la climatología fue completamente adversa con períodos de sequía al que seguían lluvias torrenciales con inundaciones

15. Domínguez Ortiz, A.: La burguesía mercantil gaditana 1650-1868. Cádiz, 1976, pp. 3-11; otros historiadores como Bustos y Ravina elevan a 7.000 los habitantes en 1600.

16. García-Baquero GonzÁlez, A.: "Cádiz y su tercio de toneladas en las flotas de Indias», Revista Gades, 1, 1978. Un tercio del tonelaje de los navíos correspondía a Cádiz y El Puerto.

17. Bustos Rodríguez, M.: «Poder económico y político en el Cádiz de la Edad Moderna», Revista Gades, 14, 1986, pp. 29-44.

18. Girard, A.: op. cit., p. 79; Ravina Martín, M.: El pleito Cádiz Sevilla por el traslado de la Casa de la Contratación. Memorial de Francisco Manuel Herrera 1726. Cádiz, 1984, p. 56.

19. Kamen, H.: La España de Carlos II. Barcelona 1984, p. 204.

Ediciones Universidad de Salamanca / 
y salidas de cauce de los ríos. El trigo duplicó sus precios en pocos años y las hambrunas dieron paso a epidemias que afectaron principalmente a Castilla. Sevilla, que había sido la ciudad más poblada de España a finales del siglo Xvi con 120.000 almas según Morales Padrón ${ }^{20}$, disponía a principios del siglo XviII de tan solo 85.000 habitantes. Otra prueba del decaimiento de la escasa industria local era la reducción de telares, que pasaron de 20.000 en el siglo xvi ocupando a más de 100.000 personas ${ }^{21}$, a solamente 300 operativos en 1722 . Además de la epidemia de peste de 1648, que había reducido la población a casi la mitad, se notaba la depresión económica de la nación sufrida en la segunda mitad del siglo XVII, y todavía no se había dado el tremendo impacto ${ }^{22}$ del traslado de la Casa de Contratación y tribunales a Cádiz. Como rezaban los Anales de Sevilla: «Este fue el primer accidente que empezó a enflaquecer el comercio de esta capital, que caminó precipitadamente hasta su ruina, y la de los establecimientos que pendían de él $\aleph^{23}$. Muchos hombres de negocios se habían trasladado a finales del siglo a la capital gaditana que, como se ha mencionado, desde 1680 era la cabecera de las flotas a Indias; encontrándose además impuestos aduaneros muy inferiores, por lo que había, al menos, un doble motivo para el traslado. Y un tercer factor importante era la mencionada facilidad para realizar maniobras de contrabando en la bahía gaditana.

La cuestión aduanera fue un factor clave en el tránsito de comerciantes de Sevilla a Cádiz, ya que la capital gaditana tenía frecuentemente un trato de favor. En Sevilla se cobraba el almojarifazgo de Indias (a partir de 1624 con peso y volumen), la alcabala y la saca. A partir de 1617 se abrió una oficina de aduana en Cádiz que no cobraba alcabalas, lo que suponía una ventaja notable. De 1635 a 1666 se crearon nuevos impuestos en Sevilla, que no se introdujeron en la capital gaditana, por lo que no es de extrañar que el comercio se desplazase a la costa ${ }^{24}$. En 1665, los comerciantes gaditanos, como se ha dicho, compraron al Rey el derecho a percibir la alcabala, que redujeron a continuación del 10 al 4\%, incrementando de esta forma el atractivo a los hombres de negocios ${ }^{25}$. Al mismo tiempo, el Rey, satisfecho con el numerario recibido, aseguraba no retirar nunca de Cádiz el comercio de Indias. Previamente, en 1661, se unificaron las tarifas

20. Morales Padrón, F.: Historia de Sevilla. La ciudad del Quinientos. Sevilla, 1977, p. 65.

21. Ravina Martín, M.: op. cit., p. 77. Cifras difíciles de aceptar.

22. Calificativo no compartido por varios autores.

23. Matute, J.: Anales de Sevilla. Sevilla, 1997, t. I, p. 115.

24. Archivo Municipal de Sevilla [en adelante AM], Sec. X, Actas Capitulares, t. XXIX, n. ${ }^{\circ} 17$.

25 Archivo Histórico Nacional [en adelante AHN], Estado, leg. 2933. Cádiz compra al Rey el derecho a percibir la alcabala, que reduce del 10 al $4 \%$.

Ediciones Universidad de Salamanca / 요 Stud. his., H. ${ }^{a}$ mod., 39, n. 2 (2017), pp. 153-184 
aduaneras a petición de Sevilla y se rebajaron todos los impuestos, con la idea de atraer al comercio y reducir el contrabando, pero esta medida fracasó al arrendar la aduana al portugués don Francisco Báez Eminente en 1663, ya que este había obtenido el contrato con la condición de que se le permitiese rebajar los impuestos a su criterio. Esta decisión supuso un freno a la vigilancia aduanera y una rebaja de impuestos para Cádiz, ya que el portugués había indicado que los negociaría con los comerciantes. La situación fiscal presentaba en Sevilla unas tasas del 30\%, mientras que en Cádiz solo se aplicaba el $4 \%{ }^{26}$. Eminente, que era un calificativo que le había dado Felipe IV y que le había permitido añadir a su nombre, consideraba que era muy conveniente para todos el que Cádiz fuese el punto focal del comercio con Indias ${ }^{27}$. Como prueba evidente de las diferencias aduaneras entre Sevilla y Cádiz, se muestra en la Tabla 1 un extracto de dichas tarifas tomadas del libro de A. Girard ${ }^{28}$ :

TABLA 1. Tarifas aduaneras en reales

\begin{tabular}{|l|c|c|}
\hline Mercancías & Sevilla & Cádiz \\
\hline 1 sombrero de castor & 61 & 8 \\
\hline 1 pieza de felpa & 274 & 40 \\
\hline 1 pieza de tela de Holanda & 335 & 24 \\
\hline 100 libras de clavo & 582 & 80 \\
\hline 100 varas de tela de Gante & 1124 & 224 \\
\hline 1 pieza de estamina & 46 & 8 \\
\hline 1 pieza de tafetán & 30 & 6 \\
\hline
\end{tabular}

El cónsul flamenco en Sevilla, Pluyms, y su colega hanseático, Acquerman, elevaron una queja a los jueces sobre el arrendador portugués ${ }^{29}$. Se quejaban de las malas prácticas de sus agentes y de llevar una política aduanera perjudicial para Sevilla y contraria a la cédula de 1661 . Con este motivo, Sevilla, a requerimiento de la Universidad de Cargadores, se dirigió a la Reina apoyando la tesis de los cónsules ${ }^{30}$; pero además, utilizó toda su influencia para evitar el estrangulamiento de su puerto. Este fue el origen de la cédula emitida por la Corona en 1664. Cuando

26. AHN, Estado, leg. 2933.

27. Más detalles en GIRARD, A.: La rivalité commerciale..., op. cit., p. 100.

28. Ibidem, Apéndice II.

29. AMS, Sec. Especial, Siglo XVIII, t. XXIX.

30. AMS, Sec. IV, Escribanía del Cabildo, t. XI, n. ${ }^{\circ} 28$. 
en 1666, el Rey ordenó el traslado de la Aduana y el Juzgado de Indias de Cádiz a Sevilla, a estas medidas añadía: la equiparación de impuestos del almojarifazgo en todas las aduanas, la puesta en vigor de las rebajas acordadas en 1661, el fin de apertura de fardos, etc. Esto supuso un duro golpe para Eminente, pero en 1668 ya había firmado un nuevo asiento ${ }^{31}$. De todas formas, la cédula real de 1666 nunca llegó a implantarse, ni en el aspecto naval, ni en el aspecto aduanero y, por supuesto, Eminente siguió beneficiando al comercio gaditano, que continuó creciendo desde 1666 a 1680. Durante los últimos veinte años del siglo xvir, los arrendadores de la Aduana beneficiaron claramente a Cádiz respecto a Sevilla. Hay un memorial muy interesante de los cónsules extranjeros de Sevilla contra Eminente donde se precisa los perjuicios causados a sus economías ${ }^{32}$.

En un informe solicitado por el Consejo de Indias a la Casa de Contratación en 1672, su presidente, Gonzalo de Córdoba, comunicaba que si se mantenía la salida de Sanlúcar las construcciones de navíos debían limitarse a las 400 o 500 toneladas, tener poco calado y como mucho dos puentes; $\mathrm{y}$ al ser su potencial bélico inferior, debía aumentarse el número de buques de escolta. Sin embargo, era partidario de hacer entrar las flotas en el saco de Puntales de la bahía gaditana, con la condición de que se mejorasen sus defensas, ya que estaban arruinadas; en ese caso, la plata desembarcada debería enviarse por tierra a Sanlúcar para una mayor seguridad. Este informe no causó el menor efecto en la Corona. Un lustro más tarde, José Veitia informaba en el mismo sentido, rectificando su postura inicial. Curiosamente, ese mismo año de 1677 entraba en Bonanza la flota del almirante general Pedro Corbet, compuesta de 27 naves, con viento NE, que era uno de los que teóricamente impedían la entrada ${ }^{33}$. Para mayor mérito, la capitana de la flota portaba 1.000 toneladas $^{34}$.

Según el viajero inglés Townsend, Sevilla había descendido en 1684 al sexto lugar entre los puertos españoles que comerciaban con América. Cádiz recibía mercancías por un valor de 3.621.443 libras esterlinas por 93.256 que recibía Sevilla; pero a pesar de todo, la capital hispalense mantenía un comercio pujante con Europa, recibiendo, entre otras, embarcaciones inglesas, holandesas, danesas y portuguesas ${ }^{35}$. Con la fuga de una buena parte de los bienes generados en el comercio de Indias, Sevilla dejó de ser lo que fue. El estamento noble fue el menos afectado por el traslado, ya que sus bienes habían sido invertidos, con preferencia, en la posesión de tierras y

31. AMS, Sec. Especial, Siglo XVIII, t. XXIX, n. ${ }^{\circ} 14$.

32. GIRARD, A.: La rivalité commerciale..., op. cit., p. 100.

33. Velázquez Gaztelu, J. P.: op. cit., pp. 284-289.

34. Se pone en duda el tonelaje indicado, aunque puede que su diseño le permitiese un calado inferior al de otros navíos de parecido tamaño.

35. Aguilar Piñal, F.: Historia de Sevilla..., op. cit., p. 195.

Ediciones Universidad de Salamanca / 뾰 Stud. his., H. ${ }^{a}$ mod., 39, n. 2 (2017), pp. 153-184 
en la agricultura. Como es bien sabido, esta era una de las metas de los cargadores a Indias y de los comerciantes importantes de la Carrera: la compra de haciendas y la aproximación a la nobleza, a ser posible con título incluido.

El cuatro de septiembre de 1691, la ciudad de Sevilla no había digerido el nombramiento de Cádiz como cabecera de las flotas y, en consecuencia, elevó a S.M. el Rey Carlos II, una consulta y súplica en la que mostraba que la Hacienda real estaba sufriendo muchos perjuicios al desplazarse el comercio de estos reinos a la ciudad de Cádiz y el Puerto de Santa María, pues al tener una bahía tan abierta era fácil el fraude y el contrabando. Aseguraba que muchos de los millones que entraban en la bahía desde las Indias pasaban a otras naciones sin pasar por el filtro aduanero. De hecho, el embajador español en Holanda, Antonio Brun, aseguraba que llegaba allí mucha plata sin registrar que había sido transbordada antes de la arribada a puerto ${ }^{36}$. Reclamaba, también, que los extranjeros vivieran a más de veinte leguas de la costa para dificultar los amaños fraudulentos. Así mismo, solicitaba que la Tabla de Indias regresase a Sevilla. A finales de siglo, la opinión general en Madrid era que el traslado a Cádiz de la Casa de Contratación y el Consulado era lo más adecuado ante la situación mercantil del momento.

\section{Proyecto y causas del traslado}

Cuando comienza el reinado de Felipe V, la Guerra de Sucesión va a paralizar todo tipo de reformas en la administración española que, por otra parte, necesitaba urgentemente para su modernización. Sin embargo, la llegada de asesores franceses enviados por Luis XIV en auxilio de su nieto se traduce en una serie de propuestas en el campo financiero, comercial y administrativo, que van a presentar al Rey para su implementación, si procede, en los momentos en que el conflicto bélico lo permita. Estos personajes llegan con la extraordinaria experiencia de una nación, que en la segunda mitad del siglo xvir ha ampliado sus dominios de forma considerable, ha mejorado sensiblemente su comercio y ha conseguido elevar la endeble marina de mediados de siglo a una potencia naval considerable. Y ¿ cómo se habían logrado estos avances? Básicamente, gracias a la dedicación y ambición de su rey y a los extraordinarios trabajos reformistas de su ministro Colbert, que abarcaban las finanzas, el comercio, la industria y principalmente, la marina de guerra. En este último apartado, le había auxiliado y luego continuado su labor, su hijo, el marqués de Seignelay ${ }^{37}$. Los métodos aplicados durante este período

36. AGI, Indiferente General, leg. 2693.

37. Tapias Herrero, E.: «Colbert y Patiño: Dos colosos en las marinas borbónicas», Revista de Historia Naval, 134, 2016, pp. 9-30. 
no siempre habían dado buenos resultados, pero lo logrado estaba a la vista. Los asesores franceses aconsejaban pero sin descuidar los intereses de Francia, sobre todo en temas que pudieran afectarles, como era el comercio. Luis XIV ya había manifestado al embajador Amelot, en 1709, que uno de los principales objetivos de la Guerra de Sucesión era la mejora en la actividad comercial francesa con los territorios americanos ${ }^{38}$.

José Patiño, durante su labor como intendente de Extremadura, y luego de Cataluña, tuvo la oportunidad de mostrar su capacidad de trabajo, visión del entorno y sentido común ante dos personas relevantes del gobierno español: Alberoni y el almirante Pes. Ambos estuvieron de acuerdo en que Patiño era la persona adecuada para encargarse de los temas navales que se pretendía potenciar, como la puesta en marcha de una nueva Real Armada y el traslado de la Casa de Contratación de Sevilla a Cádiz. Durante su estancia en Cataluña, Patiño se había iniciado en los asuntos navales al tener que conseguir navíos, en primer lugar, para el bloqueo del puerto de Barcelona, y poco más tarde, para la recuperación de Mallorca. Estudió los diseños navales del almirante Gaztañeta y propuso la construcción de dos navíos en 1716 en San Feliú de Guíxols: San Felipe el Real de 80 cañones y El Catalán de 62, al objeto de experimentar sus resultados en calidad y precios, y así poder compararlos con los construidos en Cantabria ${ }^{39}$. Tan pronto como finalizó su trabajo para la instauración del proyecto de Nueva Planta en Cataluña, partió para la Corte, donde debía incorporarse a los consejos de ministros para conocer los entresijos del comercio con Indias. Este asunto iba ligado a la protección que la nueva Marina de Guerra debía dar a las flotas que partían para Indias, pues una vez suprimido el impuesto de la avería era responsabilidad de la Corona.

El abad italiano Alberoni, que había llegado a España bajo la tutela del duque de Vendome, aprovechando su extraordinaria habilidad para las labores diplomáticas había logrado influir en la princesa de los Ursinos, verdadera cabeza del grupo francés en la Corte, para que se designase a la princesa italiana Isabel de Farnesio como candidata al nuevo matrimonio de Felipe V. Con la cercanía y protección de la nueva reina, Alberoni asumió, sin título alguno, muchos de los asuntos diplomáticos españoles, sobre todo los que sugería realizar con Inglaterra para desligarse de la tutela francesa, que desde la llegada de la nueva reina estaba mucho más difuminada. En sus escritos al embajador británico y al conde de la Rocca, ministro de finanzas

38. Kamen, H.: Felipe V. El Rey que reinó dos veces. Madrid, 2000, p. 46; Albareda Salvadó, J.: La guerra de Sucesión de España (1700-1714). Barcelona, 2010, p. 67.

39. Valdez-Bubnov, I.: «The Politics of Spanish Shipbuilding Legislation, 1607-1728», War, Trade and Technology, International Journal of Maritime History, XXI:2, 2009, pp. 75-102.

Ediciones Universidad de Salamanca / 요 Stud. his., H. ${ }^{a}$ mod., 39, n. 2 (2017), pp. 153-184 
del Ducado de Parma, manifestaba su deseo de reformar la administración española, que consideraba era muy mejorable, así como el comercio, la marina y la industria. Alberoni, con su comportamiento, don de gentes, humor y diplomacia, recordaba mucho a otro destacado italiano que triunfó de forma rotunda fuera de su país: el cardenal Mazarino ${ }^{40}$. Patiño fue pronto seleccionado por Alberoni, como milanés y como persona despierta y capaz, para llevar a cabo alguno de los proyectos de reforma. Era el momento en que un grupo de italianos había reemplazado a los asesores franceses que habían regresado a su país.

Fue así cómo al finalizar su estancia en tierras catalanas pasó a la Corte, donde el monarca le ordenó participar en las reuniones que se celebraban sobre varios proyectos relacionados con la Marina. En todas ellas participaban el abad Alberoni y el almirante Andrés de Pes, que parece era el que tenía más ascendencia sobre Felipe $\mathrm{V}$ en los temas navales. Comentaba Patiño, que allí se establecieron importantes decisiones, como el traslado de la Casa de Contratación a Cádiz, la creación de la Academia de Guardias Marinas, medidas diversas sobre el reclutamiento de marinería, etc. ${ }^{41}$. De ser ciertos estos comentarios, queda patente que Patiño sería partidario del traslado, como se verá en la justificación del voto que dio en la Junta que el Rey ordenara formar en 1722, pero que desde luego no había sido el originador del proyecto ${ }^{42}$. Parece que la propuesta venía del almirante gaditano Andrés de Pes, apoyado por Bernardo Tinajero de la Escalera, que había sido nombrado primer secretario de estado de Marina, y por Fernández Durán, que también había ocupado dicho cargo.

Pero, ¿la propuesta del almirante Pes sobre el traslado de la Casa de Contratación era original? Hay un informe de don Manuel García de Bustamante, perteneciente al Consejo de Indias en 1701, en el que se reclamaba necesaria la unión del comercio y la marina de guerra para mejorar la eficacia del monopolio comercial; con esta propuesta, Cádiz mejoraba su posición. En 1720, cuando el almirante presentó sus razonamientos ante el Rey para justificar la decisión del traslado ante las demandas sevillanas, mostró el memorial de Bustamante de 1701. Lo más curioso es que el citado memorial era, en realidad, uno de los planteamientos propuestos a finales del siglo xvir por la Junta de Comercio cuando, debido al declive económico imperante, se buscaban soluciones que reactivaran el tráfico mercantil ${ }^{43}$. En la misma ocasión, mantuvo ante $S$. M. que los tribunales de

40. Bailly, A.: Mazarino. Madrid, Espasa-Calpe, 1969.

41. Pulido Bueno, I.: José Patiño. Huelva, 1998, pp. 127-128.

42. AGI, Arribadas, leg. 10, Voto de Patiño. Se dan más detalles en página 16.

43. Tapias Herrero, E.: «El sueño del almirante Pes: el traslado de la Casa de Contratación a Cádiz en 1717», Pliegos de la Academia, 20, 2014, p. 12. 
la Casa de Contratación debían establecerse en el puerto de donde salen y entran las Armadas a Indias: "por el alivio que se hace a los comerciantes» ${ }^{44}$. El motivo era que los comerciantes debían viajar de Cádiz a Sevilla cuando surgían problemas fiscales o conflictos con los tribunales. Aprovechó para decir que no tenía información de que los comerciantes extranjeros de Cádiz hubieran mediado para obtener el traslado, y que además no entendía cómo intervenían en la demanda a la Corona el cabildo eclesiástico y el de la ciudad cuando los únicos que tenían todo el derecho para reclamar eran los comerciantes ${ }^{45}$.

Otro aspecto que decidió el traslado fue la conveniencia de centralizar el control de las flotas y de los asuntos comerciales con Indias. La Casa de Contratación llevaba tiempo mostrándose ineficaz en su trabajo, debido al sometimiento al que se encontraba abocada por el Consulado de Comercio. Con la llegada de Felipe V, Bernardo Tinajero ${ }^{46}$ desde el gabinete ministerial, espoleado por los asesores franceses que querían modernizar el tráfico naval para mejorar su posición comercial, entró en polémica con el Consulado sevillano, que se negaba a los cambios, incluso amenazando a la Corona con el bloqueo de nuevas ayudas si se accedía a lo planteado por los franceses. No es de extrañar la reacción de este organismo cuando una de las propuestas francesas planteaba su supresión. Una auditoría ordenada por la Corte llevó a la cárcel a los priores y cónsules de los años 1689 al 1705, incluyendo el embargo de sus bienes. Todos estos hechos redujeron el poder de las élites comerciales sevillanas frente a la Corona, que facilitaba la mencionada centralización del control del monopolio. Se estaba conformando la llamada vía reservada con la que el gobierno central asumía responsabilidades que hasta entonces correspondían al Consulado ${ }^{47}$.

Con la creación de la nueva Armada, que ya se encontraba en marcha, la Casa de Contratación cedía el control de las flotas a la Intendencia General de Marina. José Patiño recibiría el veintiocho de enero de 1717 la jefatura de ambas instituciones con un sueldo anual de doce mil escudos de vellón ${ }^{48}$. Como colofón, y siguiendo las pautas tomadas medio siglo antes por el ministro francés Jean Baptiste Colbert, se construiría una base naval en Cádiz que, a diferencia de los franceses, acogería y daría mantenimiento conjuntamente a las flotas de guerra y

44. Informe que el almirante Pes preparó para el Rey el 8 de marzo de 1720 tras la reclamación hispalense. Se encuentra en la Recopilación de diferentes resoluciones..., Madrid, 1722.

45. Castro, A. de: Vida del almirante don Andrés de Pes. Cádiz, 1879, pp. 46-47.

46. Uno de los principales impulsores de la reorganización naval.

47. Crespo Solana, A.: La Casa de la Contratación y la Intendencia General de la Marina en Cádiz (1717-1730). Cádiz, 1996, p. 67.

48. Fernández Duro, C.: Armada Española, t. VI. Madrid, 1973, pp. 221-223.

Ediciones Universidad de Salamanca / 요 Stud. his., H. ${ }^{a}$ mod., 39, n. 2 (2017), pp. 153-184 
mercante. Otra diferencia con la construcción del arsenal de Rochefort en 1666, es que Francia dispuso de suficientes recursos para realizar la construcción en pocos años, a diferencia del arsenal gaditano, que no progresó con la diligencia que se esperaba en terrenos de La Carraca. Otros dos arsenales serían construidos años más tarde en Ferrol y Cartagena para cubrir la periferia nacional.

Junto a Alberoni se encontraba habitualmente Miguel Fernández Durán quien, además de ser una de las personas de máxima confianza del Rey, desde 1718 aparecía como responsable de la secretaría de estado de Guerra y Marina, al que se habrían sumado también los temas ultramarinos. Los asuntos de Indias se repartían en 1715 entre las restantes secretarías de Guerra, Justicia y Hacienda. Cuando en noviembre de 1719, el Rey hizo merced a Fernández Durán de un título de Castilla como Marqués de Tolosa, era mencionado como Secretario de Estado y del Despacho Universal de la Guerra, Marina e Indias ${ }^{49}$. En 1721, la secretaría de Marina e Indias se adjudicará al almirante Pes y quedará definitivamente separada de la de Guerra ${ }^{50}$.

Por este tiempo, se creó en Sevilla un resentimiento contra Cádiz y contra Patiño, como partidario del traslado, manifestado en duras sátiras. Como ya se ha mencionado y confirman sus biógrafos, Patiño apoyaba la decisión, pero no había sido el originador del proyecto ${ }^{51}$.

\section{Reconocimientos y tRabajos En LA baRRA De SANLÚCAR}

El primer sondeo de la barra se realizó en agosto de 1666 por el marqués de Frente del Sol, entonces presidente de la Casa de Contratación, en presencia de José Veitia, tesorero y juez del citado organismo, así como de varios prácticos de altura y de la barra. Se realizaron sondeos durante siete días; en el informe se indica que la barra tiene de longitud un cuarto de legua y que el puerto de Bonanza puede albergar 300 navíos con fondos de ocho a diez brazas; las sondas con marea alta oscilaban entre los 11,8 y los $13,75 \operatorname{codos}^{52}$, es decir entre 6,5 y 7,6 metros. El segundo sondeo se realizó en 1669; en el documento explicativo de los trabajos se precisaba que la barra tenía dos canales; la del norte era utilizada solamente por buques menores, ya que calaba dos codos menos que la del sur. En esta última se habían sondado 14,6 codos a los dos tercios de marea, sin dar más detalles. El

49. Gaceta de Madrid, núm. 48, del martes 28 de noviembre de 1719.

50. AHN, Estado, 3439, exp. 34.

51. Rodríguez Villa, A.: Patiño y Campillo. Reseña histórico-biográfica. Madrid, 1882, cap. II, p. 22; Pulido Bueno, I.: op. cit.

52. Un codo equivale a 0,557 metros. 
tercer sondeo fue llevado a cabo en 1675 por el almirante Palacios por orden del Consejo de Indias ${ }^{53}$.

En 1687, siendo ya Cádiz cabecera de las flotas a Indias, el presidente de la Casa de Contratación, conde de la Calzada, presentó al Rey el proyecto de profundizar el canal de la barra a base de estrechar el caudal de agua en esa zona. Para conseguirlo se alargaría el muelle en 450 pies para estrangular el río, con la esperanza de que crecería el caudal. La Corona autorizó la obra con la condición de que sería Sevilla la que soportara los costes, por lo que el almirante sevillano Pedro Corbet inició una suscripción popular que alcanzó los 150 mil pesos. Lo curioso del caso es que se había consultado a varios prácticos de altura y de la barra, y todos desaconsejaban el proyecto. Uno de los consultados, el capitán José Moreno, Piloto Mayor de las Reales Armadas de Indias, realizó un informe por escrito razonando su postura ${ }^{54}$. El cónsul francés en Cádiz, monsieur Catalán, informaba a su ministro de Marina, marqués de Seignelay, que los trabajos durarían más de dos años; en realidad, duraron diez y el resultado fue desastroso. Probablemente desconocían que el fondo de la barra era rocoso aunque estuviese cubierto de arena y fango.

En 1701, los diecisiete gremios de mercaderes de reventas de Sevilla presentaron un memorial ${ }^{55}$ al Cabildo sevillano, en el que se mostraba el decaimiento de sus trabajos «por el mal uso del comercio de los extranjeros de Cádiz y el Puerto de Santa María con la consiguiente reducción de rentas para la Real Hacienda y en el empobrecimiento de Sevilla». La ciudad consideró oportuno elevar el documento a S. M., rogando e insistiendo, como ya se había realizado en 1691, que se restituyese a Sevilla la Tabla de Indias y el comercio en la forma en que se había mantenido con anterioridad. Con el memorial se remitía un informe sobre los sondeos realizados en el estuario del río. El Consejo de Indias estudió el documento sevillano y a través de don Manuel García Bustamante dictaminó en enero de 1702 que, si se llegaba a mejorar la entrada de Sanlúcar, habría que acercar la Casa de Contratación a la bahía de Cádiz; citando como posible lugar Puerto Real ${ }^{56}$.

El treinta de enero del mismo año, en pleno debate del Consejo de Indias acerca de la propuesta sevillana, don Juan de Castro y don Martín de Solís realizaron un voto particular en favor del retorno de la Tabla del comercio a la ciudad de Sevilla

53. Velázquez Gaztelu, J. P.: op. cit., pp. 327-328.

54. Idem, p. 291.

55. Blas y Quesada, J.: Recopilación de diferentes resoluciones y órdenes... Madrid, 1772; Archivo Histórico Universidad Sevilla (AHUS), leg. A-109/ 087 y leg. A-110/079, Memorial del 31 de mayo de 1701; AMS, Sec. XII, T. II, n. ${ }^{\circ}$ 2, rollo 89.

56. Velazquez Gaztelu, J. P.: op. cit., p. 300.

Ediciones Universidad de Salamanca / 요 Stud. his., H. ${ }^{a}$ mod., 39, n. 2 (2017), pp. 153-184 
y del puerto de Sanlúcar, siempre que los navíos no excediesen las 624 toneladas, que era lo que señalaba la ley entonces, a pesar de la opinión contraria de generales y almirantes. Aseguraban que los fondos de la barra variaban entre 14 codos en plena marea y 12 en los últimos términos del reflujo; y añadían que desde 1614 a 1664 se perdieron más bajeles en Cádiz que en Sanlúcar. En el documento de Blas y Quesada, Recopilación de diferentes resoluciones... figura un Defensorio de la Barra de Sanlúcar ${ }^{57}$ en el que la ciudad aseguraba que la barra se había pasado con navíos grandes sin ningún problema, como el construido en Santo Domingo cincuenta años atrás, de 1.200 toneladas, y en contraste, mencionaba las varadas y hundimientos acaecidos en los bajos de la bahía de Cádiz. Otro comentario hacía referencia al diferente resultado de los naufragios, ya que mientras en Sanlúcar podía rescatarse una buena parte de la carga sumergida debido a los escasos fondos, en la bahía gaditana no ocurría lo mismo. Otro aspecto a tener en cuenta era que los navíos que entraban con plata en Cádiz debían pasar luego la carga a Sanlúcar en gabarras, sin apenas protección, navegando las cinco leguas bajo graves riesgos de ataque de moros o de lanchas de buques enemigos. Por último, recordaban que según José Veitia, Cosmógrafo Mayor de la Casa de Contratación, Sanlúcar era el mejor puerto de Europa. Finalizaba el defensorio mencionando los puertos americanos de Veracruz, La Habana, Cartagena y Portobelo, explicando las dificultades que tenían tanto para entradas y salidas de buques, como incluso para su permanencia; como muestra se relataban los innumerables naufragios allí acaecidos.

La Corona reaccionó a la propuesta sevillana dando orden al presidente de la Casa para que acudiese con el almirante general Pedro Fernández de Navarrete y el almirante Antonio Gaztañeta a reconocer la barra sanluqueña y realizar nuevos sondeos, llevando como práctico al almirante Francisco Salmón, a varios oficiales de la Armada y a un grupo de pilotos y diputados de Sevilla y Sanlúcar. En marzo, Gaztañeta elevó un informe al Consejo de Indias en el que mostraba su predilección por la bahía gaditana y por la llegada de las flotas en verano donde se aseguraba el tiempo bonancible; añadía que era imposible profundizar la canal, ya que el fondo era de roca. Del dieciséis al veintitrés de agosto de 1702 se realizaron sondeos en la barra, dando como resultado que durante el primer tercio de marea podrían pasar lo bajeles que calaran menos de 8 codos. Durante el segundo tercio los que no calaran más de 10 codos, y con aguas vivas los que no sobrepasaran los 11,5 codos, es decir 6,4 metros. Estos resultados coincidían, aproximadamente, con los sondeos realizados en 1666 . Con estos datos quedaba claro que todos

57. Blas y Quesada, J.: Ibidem.

Ediciones Universidad de Salamanca / 뾰 Stud. his., H. ${ }^{a}$ mod., 39, n. 2 (2017), pp. 153-184 
los navíos que calaran más de 11 codos o, redondeando, seis metros, no deberían pasar la barra ni con marea alta.

Para entrar o salir por el río, todos los navíos de cierto tonelaje debían tener tres variables a favor: el viento, la marea y un día claro sin neblinas. Los vientos útiles para la entrada eran los cinco siguientes: N, NW, W, SW y S (los dos cuadrantes occidentales). En lo referente a la salida del río, los navíos cargados debían tener vientos del N, NE, E, y SE (cuadrantes orientales), y el agua debía estar al menos a media marea. Con respecto a los vientos dominantes durante los meses de verano se han dado opiniones encontradas, ya que Veitia Linaje aseguraba que a partir de 1620 la salida del Guadalquivir se clausuraba durante junio, julio y agosto por las dificultades de la barra; al parecer el motivo era que la marea alta venía acompañada por vientos del SW y S. Sin embargo, la estadística contradice estos datos, ya que en el período 1630-1672 de setenta y dos convoyes retenidos en Sanlúcar, veintinueve partieron durante los meses mencionados ${ }^{58}$. Con vientos NW, W, SW y $S$ era de todo punto imposible la salida. Si sucedía una encalmada a mitad de barra se podía fondear, pero los navíos con más de 9 codos podían perderse al bajar la marea. Los días claros eran necesarios para apoyarse en las marcas situadas en la costa y en las enfilaciones que utilizaban los prácticos. El fondo de la barra era roca, aunque podía encontrarse en su lecho arena, lodo o cascajo. El informe resultante fue enviado el veintidós de octubre de 1702, pero no produjo reacciones por parte de la Corona ${ }^{59}$.

El trece de enero de 1717, Sevilla, que tenía muy buena información de los rumores que circulaban en la Corte, ante la sospecha de que se estaba preparando el temido traslado de la Casa de Contratación, Consulado y Tribunales a Cádiz, remitió, una vez más, una instancia a S. M. en la que reclamaba la restitución de la Aduana y Tabla de Indias gaditanas ${ }^{60}$. Y, efectivamente, Sevilla no estaba descaminada en sus temores, pues cuatro meses más tarde, por decreto de doce de mayo de 1717 dirigido al Consejo de Indias, la Corona ordenaba que el Consulado de comercio y la Casa de Contratación pasasen a residir en Cádiz, y que esta última fuese presidida por el Intendente General de Marina. Con la caída de Alberoni en diciembre de 1719, tras el desastre de cabo Passaro, tuvieron que dejar sus cargos tanto el almirante Andrés Pes como José Patiño. Sevilla pensó que era el momento de reclamar a la Corona la anulación del traslado, apoyándose en sospechas de sobornos por parte de los comerciantes extranjeros residentes en Cádiz y designó

58. Chaunu, P.: Seville et l'Atlantique, T. VI. París, 1959, p. 302.

59. Blas y Quesada, J.: Ibidem, exp. 9, p. 65; Velázquez Gaztelu, J. P.: op. cit., p. 314.

60. AMS, Sec. XII, t. II, n. ${ }^{\circ} 19$, rollo 90. 
al almirante López Pintado ${ }^{61}$, cargador a Indias y caballero veinticuatro del Cabildo hispalense, para presentar al Rey su petición ${ }^{62}$. Felipe $\mathrm{V}$ reaccionó llamando a consultas a Pes y Patiño; una vez en su presencia, les pidió que mostrasen las razones para acometer el traslado, preguntando al mismo tiempo, si había habido alguna injerencia de los comerciantes extranjeros.

Como parte de las pesquisas, el doce de marzo de 1720, el secretario de estado Miguel Fernández Durán, de orden de S. M., ordenó a Francisco de Varas, Intendente y presidente de la Casa de Contratación, que hiciese un nuevo sondeo, que era ya el quinto, y un reconocimiento de la barra de Sanlúcar; estos trabajos se completarían con un sondeo del río. Las pruebas debían celebrarse con diferentes buques de hasta 60 o 70 cañones $^{63}$. Se encargó el trabajo al Comisario General de marina Olivares y a los ingenieros Mielson y Sánchez Tamaraz, acompañados por dos pilotos de alta mar, personas con experiencia en la barra y representantes de las tres ciudades involucradas, entre los que se encontraba López Pintado, que fue el encargado de designar a los tres pilotos que sondarían el río. Se realizaron los trabajos en mayo y junio, pero tomando sondas solamente en bajamar y extrapolando los resultados a la pleamar a base de añadir cinco codos en la barra. Esta extrapolación no resultó muy afortunada ya que, mientras las sondas de bajamar se aproximaban a las tomadas en pruebas anteriores, las deducidas para la pleamar no coincidían en absoluto. La influencia de la marea en el río mostraba que mientras en la barra se observaban los cinco codos mencionados, en Sevilla solo había dos. El ingeniero Mielson aprovechó la ocasión para proponer la construcción de tres torres de defensa situadas en Chipiona, la punta de Montijos y la punta de Malabar, al objeto de dar cierta protección a los navíos que se encontrasen fondeados en espera de poder pasar la barra. Se calculaba su coste en 90.000 reales de vellón. El informe fue remitido a S. M. el primero de diciembre y según indica Ravina fue favorable a Sevilla ${ }^{64}$.

Sevilla no se resignaba y elevó un nuevo memorial a Felipe V en 1722. Entonces, el Rey ordenó a don Luis de Miravall, gobernador del Consejo Real de Castilla, por decreto de dieciséis de julio, que formase una Junta de Ministros consultiva con objeto de debatir las instancias de Sevilla y Cádiz relacionadas con la residencia del Consulado y Casa de Contratación tras el traslado de los tribunales. Resultan muy interesantes y esclarecedoras las votaciones de los doce representantes que

61. Tapias Herrero, E.: El almirante López Pintado (1677-1745). El duro camino del éxito en la Carrera de Indias. Sevilla, 2017, pp. 223-237.

62. AMS, Idem, n. ${ }^{\circ} 22$, rollo 90.

63. Blas y Quesada, J.: Recopilación de diferentes..., op. cit., p. 76.

64. AHUS, leg. A - 023/069, p. 78; Ravina MarTín, M.: op. cit., p. 74.

Ediciones Universidad de Salamanca / 요 Stud. his., H. ${ }^{a}$ mod., 39, n. 2 (2017), pp. 153-184 
dieron una clara victoria para Sevilla por ocho votos a cuatro ${ }^{65}$. En el informe de Uztáriz, que actuaba como secretario, pero con voto, se aprecia una clara tendencia a favorecer los intereses sevillanos. Apostaba por navíos medianos en tonelaje y lo más planudos posible. En su relato hacía una comparación de siniestros producidos durante el siglo xvir entre la bahía y la barra, con cifras increíbles según informaba el gaditano Francisco Manuel Herrera en 1726. Indicaba el secretario que, mientras en la bahía gaditana se habían perdido 80 buques en la segunda mitad del siglo XVII, solo tres habían naufragado frente a Sanlúcar. Estas cifras no se sostienen con las informaciones presentadas por el hispanista Chaunu y por Serrano Mangas ${ }^{66}$. El primero hace un cómputo de naufragios hasta 1650, tanto en el río como en la bahía. Los datos globales sitúan en cabeza a Cádiz con 44 siniestros frente a 39 entre la barra y el Guadalquivir; pero de los gaditanos, quince buques fueron hundidos en el ataque del conde de Essex en 1596. Otros once buques de la flota de don Lope de Hoces naufragaron en la Bahía como consecuencia de un fuerte temporal de levante en 1635. Por contra, el hundimiento de la flota del general Roque Centeno en las inmediaciones de la barra de Sanlúcar, que el prestigioso historiador Domínguez Ortiz sitúa en 1660, no parece ser correcto ${ }^{67}$. En realidad, la flota fue diezmada por un fuerte temporal en el canal de Bahamas y el general Centeno había fallecido antes de la partida en Veracruz. El siniestro en la barra sanluqueña se produjo en 1642 y afectó, solamente, a la capitana de la flota que llegaba en precarias condiciones.

José Patiño, en su justificación del voto emitido a favor de Cádiz, manifestaba que nada había cambiado desde la decisión real del traslado de los tribunales en 1717. Observaba deficiencias en el informe del sondeo de 1720, donde no se hacía referencia al fondo rocoso de la barra, ni figuraban las firmas de los prácticos que habían realizado los trabajos, y, en resumen, apreciaba mala fe en lo ejecutado, que por otro lado era tomado como referencia por la Junta, sin tener en cuenta los sondeos previos. Recordaba que la máxima profundidad de la canal con pleamar era de 13 codos, que había que realizar tres cambios de rumbo para recorrerla, y que en alguna zona se estrechaba hasta dos mangas del navío. Aseguraba que, según los prácticos de la barra, todo navío que calase más de 10 codos a la salida o 10,5 a la entrada, estaba amenazado de tocar fondo. Recordaba que muchos seguros de riesgo no cubrían accidentes en este lugar. A continuación, mostraba una larga lista de generales y almirantes como Gaztañeta, Salmón, Fernández Navarrete, el príncipe de Montesacro, Fernández de Córdoba, Gaspar de Palacios, etc., que

65. AMS, Sec. XII, t. II, n. ${ }^{\circ} 27$, rollo 90.

66. Chaunu, P.: Seville et l'Atlantique..., op. cit., t. VI.2, p. 303.

67. Domínguez Ortiz, A.: Orto y ocaso en Sevilla. Sevilla, 1974, p. 139.

Ediciones Universidad de Salamanca / 요 Stud. his., H. ${ }^{a}$ mod., 39, n. 2 (2017), pp. 153-184 
consideraban impracticable la entrada en Sanlúcar para navíos de cierto porte e incluso para fragatas. Era partidario de no reducir el tonelaje de nuevas construcciones, como proponían Uztáriz y otros diputados sevillanos, ya que además de ofrecer una mayor seguridad en la mar con mal tiempo, debían mantener similar tonelaje que el de los buques enemigos. Decía José Veitia que se había creado el Consulado en Sevilla porque era el lugar donde se asentaban la mayoría de los comerciantes; pues bien, el número y poder económico de cargadores y cosecheros de la Bahía de Cádiz superaba claramente a Sevilla en ese momento, como podía comprobarse en la carga de las flotas. Por último, en lo referente a los fraudes y contrabando que dicen se dan en la bahía, habría que señalar que el saco de Puntales y sus caños ofrecen una mayor seguridad y la separación necesaria de los navíos extranjeros, susceptibles de transbordos ilegales, ya que estos fondeaban en la bahía. Con estas apreciaciones no tenía sentido anular el traslado de la Casa de Contratación y sus Tribunales, así como el Consulado ${ }^{68}$.

El 31 de octubre de 1722 el almirante Gaztañeta informaba al almirante Pes que, llegando de la mar rumbo a Bonanza, lo primero que se encuentra es el bajo de Salmedina; desde este lugar hasta la Punta del Perro hay una canal por la que solo se puede navegar con marea alta. El bajo de Salmedina se encuentra al NW de la Punta de Chipiona y al NE de este bajo se localiza otro de piedra más peligroso: el Picacho. Desde Galoneras (comienzo de la canal) hasta la Cabeza de las dos Rizas hay 325 brazas; y desde aquí, hasta encontrarse N/S con Juan Pul, hay 220 brazas y esta es la parte de la canal que los prácticos llaman del Sur. La parte norte de la canal tiene un ancho de 110 brazas, por lo que bajeles no muy grandes pueden ganar barlovento. Además de la canal Sur mencionada, que es la más utilizada, hay otros dos canales llamados del Norte y Nuevo, solamente útiles para embarcaciones menores. Luego hay otros dos bajos peligrosos: las Tres Piedras y la Rizeta; el ancho de la canal en esa zona es de 320 brazas, por lo que el peligro es relativo. Después de haber pasado el Bajo de la Rizeta no hay ningún peligro de banco o bajo hasta el surtidero de Bonanza, que es donde quedan fondeados los navíos.

Gaztañeta continúa el informe haciendo referencia al sondeo de 1720 en el que se utilizaron varas o picas para medir los codos o medios codos de sonda, ya que las grandes corrientes no permitían mantener los cordeles tensos en los escandallos, con lo que se desvirtuaba la sonda. En el extremo de las picas se colocaba sebo para tomar muestras del fondo; allí se vio que, aunque en zonas aparecía lama o arena, el fondo era de roca dura en toda la canal. Recordaba las

68. AGI, Arribadas, leg. 10, Voto de Patiño.

Ediciones Universidad de Salamanca / 요 Stud. his., H. ${ }^{a}$ mod., 39, n. 2 (2017), pp. 153-184 
tres condiciones ya mostradas para pasar la barra, y aseguraba que, en ocasiones, habían entrado buques grandes con viento contrario navegando de bolina con la ayuda de los prácticos. En el memorial de Sevilla de 1722 se mencionaban todas las flotas que pasaron la barra sin problemas, haciendo hincapié en la de 1677 del almirante Pedro Corbet que, con 27 navíos y una capitana de más de 1000 toneladas, atravesaron la canal con viento contrario del ENE navegando de bolina por la canal ${ }^{69}$. Continuaba informando Gaztañeta que cuando llegaban flotas numerosas en invierno con vientos fuertes del sur que provocaban travesías en los fondeaderos, al no saber si podrían pasar la barra, preferían entrar en la bahía de Cádiz. Para facilitar la entrada de noche en la bahía, se colocaban lanchas con faroles en los bajos del Diamante y Las Puercas. Una vez que los vientos se tornaban favorables, navegaban con rumbo a Sanlúcar y fondeaban en los Pozos de Chipiona esperando el momento de cruzar la barra.

\section{Navegación del Almirante López Pintado de Cádiz a Bonanza}

Pero en el proceso de la decisión real sobre el traslado de la Casa de Contratación faltaba un importante trabajo de los previstos: el cruce de la Barra de Sanlúcar por un navío de 60 cañones, que hasta entonces no se había podido llevar a cabo. El almirante don Manuel López Pintado recibió del marqués de Grimaldo la orden real del treinta de junio de 1723, por la que debía salir de Cádiz y cruzar la barra de Sanlúcar con un pingue de su propiedad, Nuestra Señora de Begoña, que acababa de llegar de Indias ${ }^{70}$. La orden precisaba que el buque debía encontrarse lastrado de igual forma que cuando hizo el viaje de regreso «para reconocer la capacidad de este puerto y su fácil entrada para navíos de fuerza». El buque se decía que cumplía con lo previsto al tener una capacidad de carga de 800 toneladas y portar 60 cañones. En la derrota a seguir, saldría de Cádiz acompañado por el capitán de fragata don Francisco Álvarez Cuevas, expresamente designado por S. M., y con el escribano real don Luís de Valderrama y Galván para que tomase nota de todas las maniobras. Entraría por la canal de Sanlúcar al puerto de Bonanza para regresar a continuación a Cádiz. El almirante podría elegir todo el personal de pilotos, oficiales y gente de mar necesarios, y el coste de la operación recaería sobre la ciudad de Sevilla ${ }^{71}$. Para asegurarse que el calado del buque era el mismo que trajo desde las Indias en su última navegación, se tomó declaración al piloto

69. AHUS, leg. A-109/087.

70. Biblioteca Nacional [en adelante BN], mss. 11856, p. 1, Carta del marqués de Grimaldo al almirante don Manuel López Pintado.

71. AHN, Estado, leg. 2933, Carta sin fecha ni remitente o destinatarios.

Ediciones Universidad de Salamanca / ف®@ Stud. his., H. ${ }^{a}$ mod., 39, n. 2 (2017), pp. 153-184 
mayor capitán Manuel Antonio Gutiérrez, al contramaestre Diego Antonio Vidal, vecino de Sanlúcar, así como a otros oficiales y gente de mar que navegaron en ese viaje y que regresaron de Tierra Firme en la flota mandada por el teniente general don Gaspar de Guevara. Todos ellos aseguraron que en la salida de La Habana calaba nueve codos y cuarto a popa, y ocho y cuarto a proa, y que venía «con su carga regular para sostener sus gavias». El contramaestre informó que en esa navegación su capitán era don Gabriel Cordobés Pintado ${ }^{72}$. También se le pedía al almirante que comprobara los sondeos y reconocimientos que se habían realizado en años anteriores en la canal y puerto para asegurar su certeza ${ }^{73}$.

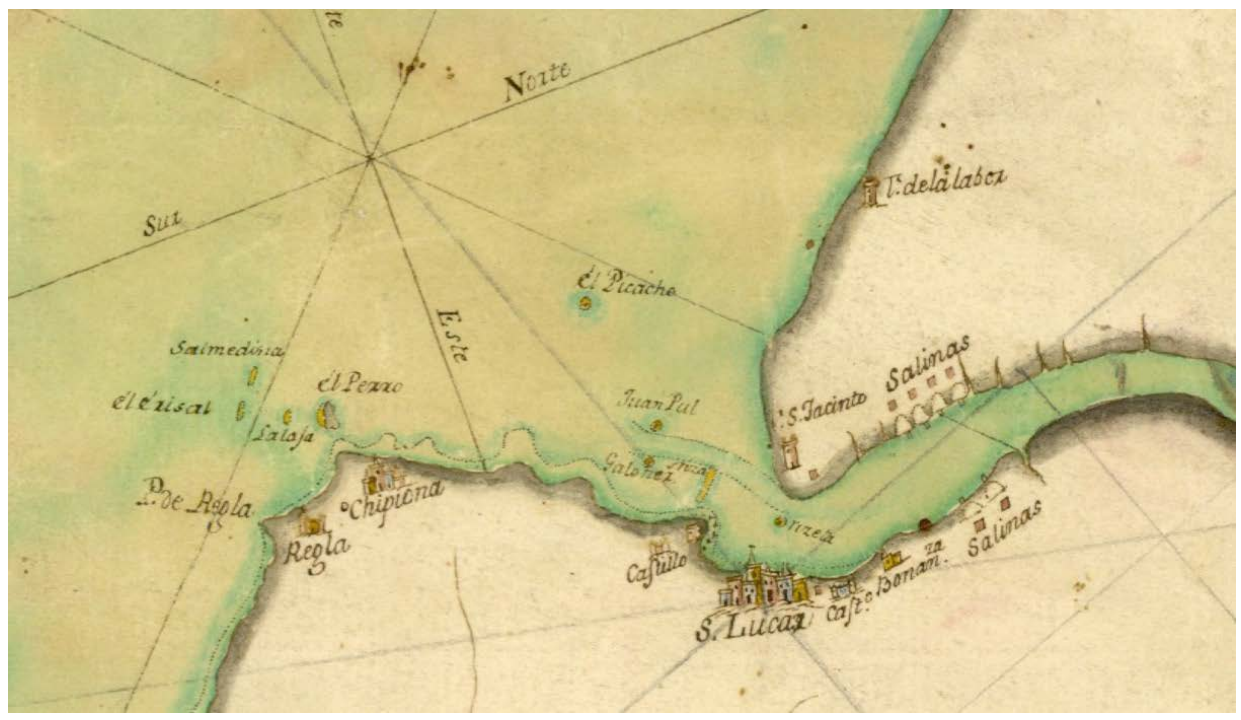

IMAgEN 1. Barra de Sanlúcar ${ }^{74}$.

Para la realización de la prueba, la Corona exigió que se colocaran en puntos destacados de la canal a personas relevantes de Sanlúcar, con objeto de asegurar la corrección de las pruebas. Entre los testigos figuraban: el alcalde de la mar y piloto de la canal, Diego de Medina; el regidor don Pedro Manuel Durán Tendilla;

72. Sobrino de López Pintado y futuro prior del consulado en 1764.

73. Biblioteca Capitular Colombina [en adelante BCC], Papeles Varios 33-5-30 (66) de 1726.

74. Archivo Cartográfico del Ejército, Mapas y Planos, p. 393. Barra Sanlúcar y río Guadalquivir. 
el alguacil mayor y alcalde honorífico Francisco Gil de Ledesma Sotomayor, así como el escribano público Manuel José Romero. Estas personas, con algunas más, se colocarían en diversas embarcaciones en cuatro conocidos puntos de la canal: Galoneras, Juan Pul, Cabeza de las dos Rizas y Rizeta. El veinte de agosto, a primera hora de la mañana ante el escribano real, se tomó declaración a Manuel Antonio Gutiérrez, piloto de altura, a Bernardo Peláez, contramaestre, a Joseph Luidado, guardián, a Francisco de Ojeda, despensero y a Diego Balsero, condestable. En presencia del capitán de fragata Álvarez Cuevas, todos confirmaron que el navío calaba ocho codos y cuarto largos a proa y nueve codos y cuarto largos a popa ${ }^{75}$.

Entre las cinco y seis de la mañana del día 20 de agosto el escribano certificó el comienzo de la navegación con viento sur una vez abandonado el fondeadero de Cádiz. A las catorce horas, el piloto práctico de la canal y puerto de Bonanza, Bartolomé Medina, confirmó que el buque se encontraba en los Pozos de Chipiona. El almirante ordenó se disparara un cañonazo para indicar a los testigos que comenzaban las pruebas. Se puso a la capa y allí mismo se realizó la primera sonda que dio veinticuatro codos reales, mostrando el escandallo lama suelta. Inició la navegación en busca de la canal tomando sondas de forma continuada desde la lancha auxiliar; hasta la entrada de la canal se realizaron treinta y una sondas, las diecinueve primeras dieron la misma profundidad, pasando la calidad del fondo de lama a arena dura. A partir de aquí, la sonda se reducía hasta alcanzar a la entrada de la canal, norte-sur de Galoneras, una profundidad de catorce codos con arena dura. Desde el comienzo de la canal se realizaron diecisiete sondas hasta el segundo punto relevante de la misma: el Pozo de Barronal. En este tramo, la sonda séptima y octava dieron el mínimo: trece codos y medio con arena dura. La novena y décima, frente a Juan Pul, dieron ya catorce codos y medio y cascajo. Luego entraron en el mencionado pozo Barronal con quince y medio; la sonda fue aumentando hasta los diecinueve codos y luego disminuyendo hasta los dieciséis y medio en el Pozo de la Villa. Desde aquí, las sondas ascendían hasta los veinticuatro codos, finalizando entonces las mediciones, pues el práctico aseguró que se mantenía la misma profundidad de veintidós codos hasta el punto de fondeo, entre el Castillo del Salvador y la Venta de Bonanza, a donde se llegó a las quince treinta horas. López Pintado ordenó a su piloto que registrara ante el escribano la derrota seguida desde Cádiz, con rumbos y vientos, para que constase en acta, lo que realizó el día veintiuno ${ }^{76}$. Es de suponer que el almirante jugaba con alguna ventaja, ya que el tiempo era bueno y, además, calculó la salida de Cádiz para estar

75. BN, mss. 11856, pp. 10-12.

76. BN, mss. 11856, pp. 12-16. 
en los Pozos de Chipiona a tiempo para cruzar la canal con media marea, como ya había indicado con antelación.

El regreso a Cádiz se realizó el tres de septiembre ${ }^{77}$ a las cuatro de la madrugada con viento del nordeste, navegando por el veril contrario al de la entrada y, de noche, para confirmar que era posible una navegación segura. Las mínimas sondas fueron de trece codos y medio. A las seis de la mañana se encontraba en mar abierto, fuera de la canal. Aseguran los prácticos que, cuando el navío salió de la canal, la marea estaba menguando desde hacía hora y media. Para lastrar el navío se utilizaron diecisiete pipas de agua salada y una barcada de pinos verdes de la tierra. López Pintado puso reparos a los informes suministrados por el ingeniero don Alberto Mienson años atrás, en el sentido de que no era cierto que en los Pozos de Chipiona se estaba resguardado de los vientos del este, norte, sur y sudeste. Para dar una mayor solidez a su opinión, formó una Junta de pilotos del canal y del puerto, y ante el escribano redactó un informe en el que aseguraban que el fondeadero solo estaba protegido de vientos del sudeste, del sur y del sudoeste, y además, no combatían las corrientes ${ }^{78}$. En 1726 el ayuntamiento de Sevilla solicitaba al Rey que mantuviese las elecciones de cónsules de la Casa de Contratación en Sevilla, pues Cádiz las reclamaba y que, como muestra de lealtad a la Corona, construiría a su costa unas torres de defensa para proteger el fondeadero de los Pozos de Chipiona, que se encontraban expuestos al ataque enemigo mientras los navíos esperaban el momento oportuno para cruzar la barra ${ }^{79}$.

En principio, no parecía justo hacer una prueba tan importante por medio de un representante sevillano y no contar con testigos de la parte contraria. Pero los gaditanos, alertados de la comisión, prepararon un barco longo y una falúa para observar a distancia las maniobras del navío. Al final, culparon al almirante de ayudarse con algunas embarcaciones auxiliares para pasar la canal sin riesgo y, además, añadían que ni la carga ni los cañones eran los estipulados; también se quejaban del secretismo que rodeó a la navegación. El resumen crítico de la navegación de López Pintado lo realiza de forma oficial el diputado por Cádiz don Francisco Manuel Herrera, que contesta a S. M. sobre las anomalías encontradas en la navegación del almirante con su navío Ntra. Señora de Begoña. Decía que

77. Es decir, dos semanas después de la entrada.

78. BCC, Ibidem; AHUS, AFD/ 0094(02), Copia de las diligencias ejecutadas por el Almirante Real Don Manuel López Pintado, Caballero del Orden de Santiago, en la entrada, y salida por la Canal de Sanlúcar, y Puerto de Bonanza, del Navío nombrado Nuestra Señora de Begoña, que se ejecutó el día veinte de agosto del año pasado de mil setecientos y veinte y tres, en virtud de Real Orden de su Majestad.

79. BCC, Papeles varios T.V, Sevilla. Ayuntamiento. Ordenanzas s. XVIII. 33-5-30.

Ediciones Universidad de Salamanca / 요 Stud. his., H. ${ }^{a}$ mod., 39, n. 2 (2017), pp. 153-184 
Sevilla había propuesto este buque que, según ellos, debería poder montar 60 o 70 cañones, tal como se había ordenado en su real orden de 5 de julio de 1723 y que debería tener 800 toneladas. Constaba por la Contaduría del Tribunal de la Contratación que, en realidad, el navío solo alcanzaba 403 toneladas y según indicaban los maestros mayores de las maestranzas había montado regularmente 22 cañones de a 6 y, a media carga, lo más que podía montar era 34 piezas de a 8 . Pero cuando salió para iniciar la prueba solo montaba 21. El navío con su cargamento regular debería calar 8 codos, pero en su salida solo alcanzaba 7, y muy lejos de los 15 que sería lo normal en los navíos que viajaban a Indias con 60/70 cañones. Se quejaba, así mismo, de que no se había invitado a ningún representante gaditano a pesar de haberlo dispuesto S. M. Además, se había lastrado el navío con agua y arena que podía fácilmente aligerarse. La marca de proa que limitaba la máxima carga se encontraba 16 pulgadas fuera del agua y, la cinta del costado que mostraba asimismo el límite transportable, estaba 8 pulgadas por encima de la línea de flotación. En resumen, el navío calaba un codo menos de lo que debería. En plena canal comprobó que no llevaba la carga regular ordenada y en consecuencia, durante la noche del día 27, en el fondeadero de Bonanza, se embarcaron 7 u 8 lanchadas de arena y 30 pipas de agua salada. Para iniciar la navegación de regreso tuvo que esperar catorce días hasta que las condiciones fueron favorables para pasar la barra. Entonces, salió de noche con una lancha por la proa, con práctico, y ayudado de faroles ${ }^{80}$.

El informe redactado por López Pintado el seis de septiembre era favorable a Sevilla ${ }^{81}$; pero Cádiz, como se ha señalado, protestó mostrando las irregularidades mencionadas ${ }^{82}$. El almirante se defendió de las denuncias alegando mala fe en los escribanos gaditanos y demostró en un documento, que apoyaban varios testigos, la falsedad de las acusaciones ${ }^{83}$. Con esta navegación Felipe V mostraba su confianza en la experiencia del marino sevillano y, aunque no dudaba de su honestidad, ya que sabía que sus negocios comerciales dependían probablemente de su informe final, decidió nombrar a un capitán de fragata como observador, así como a un escribano, para asegurar la fiabilidad de las pruebas. López Pintado se enfrentaba con su honor profesional, que le impedía torcer o matizar su informe en favor de los intereses sevillanos. Podía aceptarse que la canal se cruzaba sin dificultades con un navío de 800 toneladas cargado (aunque los gaditanos aseguraban que solo alcanzaba 403), incluso sin aprovechar el repunte de la marea,

80. AHUS, legajo A -023/069; Ravina Martín, M.: op. cit, p. 91.

81. AHN, Estado 2933, López Pintado a Grimaldo.

82. AMC, Reales Órdenes, legs. 4 y 5.

83. BN, mss. 11856, p. 46 y 57. 
pero a esto había que añadir que las condiciones en las que se navegó eran las ideales. Cuando se regresaba de Indias en una gran flota, no se podía disponer fácilmente de estas condiciones de marea, mar y viento. De hecho, los gaditanos se quejaron del retardo de dos semanas en el regreso a Cádiz, prueba de que las tres variables mencionadas, además de un mínimo de visibilidad, no se presentaban tan fácilmente para el paso franco. El autor ha realizado unas catas con datos de vientos facilitados por los partes de Vigía de la Torre Tavira de Cádiz durante el primer tercio del siglo XIX ${ }^{84}$, y se ha podido apreciar que, en agosto, los vientos de componente levante necesarios para efectuar la salida, se daban solamente entre dos y seis días; de esta forma se entiende el retardo en el regreso del almirante ${ }^{85}$.

\section{Conclusión}

En las páginas anteriores se han mostrado los múltiples factores que influyeron en la decisión real del traslado de la Casa de Contratación, como: la debilidad e ineficacia de la institución en ese momento; el excesivo predominio del Consulado de comercio sevillano sobre el control de las flotas y el comercio transatlántico; la decisión del gobierno de centralizar los controles mencionados por medio de las nuevas secretarías de estado y de la recién creada Intendencia General de Marina; los problemas en la navegación por el río y barra; y, por último, el proyecto de crear en Cádiz una gran base naval que diera asistencia y protección a las flotas de guerra y mercante.

Pero en este trabajo nos hemos comprometido a resaltar los aspectos navales que condicionaron la decisión del traslado. Se ha explicado la evolución en tonelaje de los navíos desde el comienzo de la Carrera de Indias, y cómo ya a finales del siglo xvi los buques con calado superior, como eran los escoltas y algunos mercantes, encontraban dificultades para descender el río cargados y ya no digamos para pasar la barra de Sanlúcar. Se ha mencionado en la Introducción, que en 1588 el duque de Medina Sidonia solicitó permiso a Felipe II para que sus naves capitana y almiranta pudieran salir desde Cádiz a causa de los problemas para atravesar la barra. En diciembre de 1628 una cédula real prohibía construir navíos de más de 550 toneladas $^{86}$, precisamente para evitar los problemas de navegación en el Guadalquivir, y esto ocurría cuando las demás naciones incrementaban el tonelaje de sus buques por resultar más rentables. En 1655, se realizó una consulta

84. No existían datos en el xviII.

85. García Herrera, R.: El clima de Cádiz en la primera mitad del siglo XIX según los partes de la Vigía. Cádiz, 2008.

86. Veitia Linaje, J.: op. cit., p. 78. 
a generales que no eran partidarios de arribar en el tornaviaje a Sanlúcar para conocer sus razonamientos; estos, solo estaban de acuerdo en la utilización del citado puerto si se limitase a 600 el tonelaje de los navíos, y en ese caso, con la condición de efectuar la entrada en el río en verano, ya que entonces los vientos resultaban más favorables y no solían darse los temidos vendavales invernales. Pero limitar el tonelaje de los buques suponía quedarse retrasados con respecto a las políticas de construcción de las demás naciones europeas. Además, el no permitir un mayor potencial bélico en los bajeles exigía el aumento del número de escoltas para no perder capacidad defensiva. En el aspecto mercantil afectaba a una pérdida de competitividad en lo referente a los fletes. Pero había otra salida al problema de acuerdo con la ingeniería naval: el aumento del tonelaje en las nuevas construcciones sin incrementar el calado. En este apartado, los holandeses eran unos expertos, ya que estaban rodeados por aguas poco profundas; en este sentido, parecía oportuno realizar misiones de espionaje o contratar constructores cualificados.

Se entiende que la Corona tuviera razones para mantener la institución en Sevilla, dada la gran influencia y peso económico del Consulado de comercio y de personajes relevantes de la nobleza y burguesía hispalense, que dominaban los corredores de la Corte. Además, quedaba claro que el control aduanero podía ser mucho más riguroso en Sevilla que en Cádiz. Pero si nos concentramos en los factores navales, es indudable que la solución gaditana salía triunfante de forma definitiva. No se puede comparar la entrada en una amplia bahía con una canal de entrada perfectamente definida para evitar los bajos, y con sondas que permitían la entrada de todo tipo de navíos, con los problemas que había que afrontar en el paso por la barra de Sanlúcar. Aquí, además de las limitaciones en el calado, eran clave factores como viento, marea y condiciones meteorológicas apropiadas. Como ya avanzamos, la buena visibilidad era también importante para distinguir las marcas y enfilaciones para la navegación por la canal. Si analizamos la seguridad de los buques, vemos que ya en 1702, con ocasión del ataque anglo-holandés, los fuertes de Puntales y Matagorda, recientemente reforzados, protegían sólidamente la bahía interna gaditana. Por el contrario, los navíos que encontrasen condiciones adversas a la entrada del río debían fondear en los pozos de Chipiona, en espera del momento del paso de la barra, desprotegidos ante la amenaza de ataques piratas o corsarios, o la llegada de temporales que podían resultar desastrosos. Este era el problema que se presentaba cuando las flotas encontraban a su regreso vientos de levante que les impedían la entrada y que podían durar varias jornadas. Todo esto sin mencionar que los navíos grandes debían desembarcar parte de su carga en la playa de Chipiona para poder pasar la barra; luego, la recuperarían en Bonanza o se transportaría a Sevilla con otras embarcaciones menores.

Ediciones Universidad de Salamanca / 요 Stud. his., H. ${ }^{a}$ mod., 39, n. 2 (2017), pp. 153-184 
Se han detallado los vientos necesarios tanto para la entrada como para la salida del río, así como las limitaciones por mal tiempo o vientos frecuentes durante varios períodos del año. Con todo este cúmulo de condicionantes parece imprudente someter a grandes flotas a la incertidumbre de poder entrar en puerto al final de una larga navegación. Máxime, cuando hay una alternativa fácil al alcance de la mano, aunque ello suponga el declive comercial de una gran ciudad como es Sevilla. Curiosamente, Sanlúcar se desligaba de su simbiosis con Sevilla al considerar en 1778 que había mejorado su economía con el traslado de la Casa de Contratación a Cádiz ${ }^{87}$. Y en los problemas de salida del río tenemos múltiples ejemplos de flotas retenidas hasta tres meses, como le ocurrió a la flota del general Larraspuru en 1630, o a la de don Nicolás de Córdoba en 1664. El conde de Villalcázar tuvo que esperar un mes en 1666 para conseguir las condiciones favorables ${ }^{88}$, y algo parecido le ocurrió a la flota de don Enrique Enríquez en $1668^{89}$. Pero el potencial político de la ciudad hispalense era grande en Madrid y si se produce el traslado es por la decisión firme del cardenal Alberoni, primer ministro in pectore, aconsejado por el almirante Pes, que tenía la confianza absoluta de Felipe V en todo lo relacionado con los temas navales y mercantiles con Indias. Patiño se encontró con la decisión tomada, según comunicaba a Fernández Durán en 1720, pero la secundaba plenamente ${ }^{90}$.

La prueba realizada por el almirante López Pintado en 1723, para comprobar la dificultad de paso de un navío de 800 toneladas en situación que debía ser similar al regreso de un viaje a Indias, no demostró que fuera un paso fácil, ya que se realizó en condiciones extraordinariamente buenas de mar, viento y marea. En cualquier caso, se apreció bajo la quilla un margen de cuatro codos, es decir, dos metros de agua. Las sondas mínimas experimentadas por el almirante con marea alta coincidían con las detectadas por los sondeos de 1666 y los de 1702 de Fernández de Navarrete, antes mencionados. De todas formas, estas medidas se realizaban con marea alta apoyándose en óptimas fases de la luna. La canal, que tenía un cuarto de legua de longitud, presentaba un estrechamiento que, según cuenta Veitia que vivió los sondeos de 1660 como secretario de la Casa de Contratación ${ }^{91}$, tenía solamente 30 metros, es decir que un navío de 600 toneladas con diez metros de manga tenía un margen similar a su manga por cada banda para no

87. Velázquez Gaztelu, J. P.: op. cit., pp. 361-362.

88. Serrano Mangas, F.: Naufragios y rescates en el tráfico indiano durante el siglo XVII. Lima, 1991, p. 28.

89. AGI, Arribadas, leg. 10.

90. Pérez Fernández-Turégano, C.: Patiño y las reformas de la administración en el reinado de Felipe V. Madrid, 2006, p. 145

91. Girard, A.: op. cit., p. 153. 
encallar. El presidente de la casa en 1672, Gonzalo de Córdoba, aseguraba que el ancho mínimo era de dos mangas y sin embargo, Uztáriz, en su amplio resumen de las reuniones de la Junta de 1722, aseguraba que era mucho mayor (indicaba 221 brazas o 442 varas castellanas, que es una barbaridad, salvo que se haya deslizado un error de transcripción $)^{92}$.

Para atravesar la barra de regreso a Cádiz, López Pintado tuvo que esperar dos semanas para encontrar las condiciones ideales que le aseguraran el paso franco. A pesar de que el informe del almirante fue positivo, no hay que olvidar ni las alegaciones gaditanas, ni que el marino había sido el representante de Sevilla en las primeras reclamaciones a la Corona en 1720. De hecho, la Corona, en su decisión inicial de 1725 de retorno a Sevilla de la institución, no adoptaba solución alguna respecto a la entrada de flotas en Sanlúcar. Por otro lado, hay que pensar que lo que se consideraba no era el paso de un navío, sino el de flotas de muchas unidades que entraban o salían del río al mismo tiempo. Adoptando la solución gaditana no habría problema alguno en aumentar el tonelaje de las embarcaciones. Con posterioridad a los tiempos mencionados, los buques fueron alargándose en eslora y disminuyendo su calado, lo cual les permitía pasar la barra aún desplazando miles de toneladas. Hoy en día, el calado máximo de la barra en pleamar y con unos buenos coeficientes de marea es de 7 metros a la entrada y de 6,40 a la salida ${ }^{93}$. La evolución sufrida por la ingeniería naval permite ver en la actualidad navíos que han pasado la barra con desplazamientos de hasta 30.000 toneladas.

Según el historiador Allan Kuethe fueron factores políticos más que geográficos los que determinaron el traslado ${ }^{94}$. Podría ser, pero en cualquier caso, los problemas en la navegación por el río, aquí planteados, eran sumamente importantes y se solucionaban apostando por la bahía gaditana, como así sucedió.

\section{BiBLIOGRAFÍA}

Aguilar Piñal, F.: Historia de Sevilla en el siglo XVIII. Sevilla, Universidad de Sevilla, 1982. Albareda Salvadó, J.: La guerra de Sucesión de España (1700-1714). Barcelona, 2010.

Bailly, A.: Mazarino. Madrid, Espasa-Calpe, 1969.

Bernard, G.: «La Casa de la Contratación de Sevilla, luego de Cádiz en el siglo XviII», Anuario de Estudios Americanos, 12, 1955, pp. 253-286.

BLAS y QUESADA, J.: Recopilación de requisiciones en el conflicto Sevilla-Cádiz. Madrid, 1772.

92. AMS, Sec. XII, T. II, Exp. n. ${ }^{\circ}$ 26. Voto de Uztáriz el 31.12.1722.

93. La diferencia viene explicada por la onda de marea entrante.

94. Kuethe, A. J.: «Traslado del Consulado de Sevilla a Cádiz», en Relaciones de poder y comercio colonial: nuevas perspectivas. Sevilla, 1999, p. 64.

Ediciones Universidad de Salamanca / 요 Stud. his., H. ${ }^{a}$ mod., 39, n. 2 (2017), pp. 153-184 
Bustos Rodríguez, M.: «Poder económico y político en el Cádiz de la Edad Moderna», Revista Gades, 14, 1986, pp. 29-44.

Bustos Rodríguez, M.: Burguesía de negocios y capitalismo en Cádiz: los Colarte (16501750). Cádiz, 1991.

Cano Revora, G. y Torrejón Chaves, J.: «Arbitrios y fortificación: la financiación de las murallas de la ciudad de Cádiz durante el siglo xviII», en Fortea Pérez, J. I. y Cremades Griñán, C. M.: Política y Hacienda en el Antiguo Régime. Actas de la II Reunión Cientifica de la Asociación Española de Historia Moderna Moratalla (1992), vol. 1. Murcia, 1993, pp. 185-202.

Castro, A. de: Vida del almirante don Andrés de Pes. Cádiz, 1879.

Comellas, J. L.: Sevilla, Cádiz y América. El trasiego y el tráfico. Málaga, 1992.

Chaunu, P.: Seville et l'Atlantique, T. VI y VIII. París, 1959.

Chaunu, P.: Sevilla y América siglos XVI y XVII. Sevilla, 1983.

Crespo Solana, A.: La Casa de la Contratación y la Intendencia General de la Marina en Cádiz (1717-1730). Cádiz, 1996.

Crespo Solana, A.: «La acción de José Patiño en Cádiz y los proyectos de la Corona en el siglo XVIII», Revista Trocadero, 5-6, 1994.

Cuesta, D.: La Casa de Contratación de Sevilla. Jornadas de Historia Marítima. Madrid, Instituto de Historia y Cultura Naval, 2001.

Díaz Blanco, J. M.: Así trocaste tu gloria. Guerra y comercio colonial en la España del siglo XVII. Madrid, 2012.

Domínguez Ortiz, A.: Orto y ocaso en Sevilla. Sevilla, Universidad de Sevilla, 1974.

Domínguez Ortiz, A.: La burguesía mercantil gaditana 1650-1868. Cádiz, 1976.

Fernández Cano, V.: «Disputa por la sede de la Casa de la Contratación en 1725», Anuario de Estudios Americanos, 26, 1969, pp. 357-383.

Fernández Duro, C.: Armada Española desde la Unión de los reinos de Castilla y Aragón. T. VI. Madrid, Museo Naval, 1973.

García-Baquero GonzÁlez, A.: "Cádiz y su tercio de toneladas en las flotas de Indias», Revista Gades, 1, 1978.

García Herrera, R.: El clima de Cádiz en la primera mitad del siglo XIX según los partes de la Vigía. Cádiz, 2008.

GIRARD, A.: La rivalidad comercial y maritima entre Sevilla y Cádiz hasta finales del siglo XVIII. Sevilla, Renacimiento, 2006.

Kamen, H.: La España de Carlos II. Barcelona, 1984.

Kamen, H.: Felipe V. El Rey que reinó dos veces. Madrid, 2000.

Kuethe, A. J.: «Traslado del Consulado de Sevilla a Cádiz», en Relaciones de poder y comercio colonial: nuevas perspectivas. Sevilla, 1999.

Martínez Navas, I.: «Alberoni y el gobierno de la Monarquía española», REDUR, 8, 2010, pp. 63-110.

Morales Padrón, F.: Historia de Sevilla. La ciudad del Quinientos. Sevilla, 1977.

Ediciones Universidad de Salamanca / 요 Stud. his., H. ${ }^{a}$ mod., 39, n. 2 (2017), pp. 153-184 
ENRIQUE TAPIAS HERRERO

ASPECTOS NAVALES EN EL TRASLADO DE LA CASA DE CONTRATACIÓN

Pérez Fernández-Turégano, C.: Patiño y las reformas de la administración en el reinado de Felipe V. Madrid, IHCN, 2006.

Pérez-Mallaína Bueno, P. E.: Política naval española en el Atlántico 1700-1715. Sevilla, EEHA, 1982.

Piernas y Hurtado, J. M.: La Casa de la Contratación de las Indias. Madrid, 1907.

Ponce Cordones, F.: Rota 1702. Un episodio olvidado de la Guerra de Sucesión. Cádiz, 1979.

Pulido Bueno, I.: José Patiño. Huelva, 1998.

Ravina Martín, M.: El pleito Cádiz Sevilla por el traslado de la Casa de la Contratación. Memorial de Francisco Manuel Herrera 1726. Cádiz, Diputación Provincial, 1984.

Rodríguez Vicente, E.: «Apelaciones de la casa de contratación y Consulado de Cádiz ante el Consejo de Indias: inventario de la documentación existente en el Archivo Histórico Nacional de Madrid», Revista de la Universidad Complutense, 107, 1997, pp. 143-244.

Rodríguez Villa, A.: Patiño y Campillo. Reseña histórico-biográfica. Madrid, 1882.

Serrano Mangas, F.: Los galeones de la Carrera de Indias 1655-1700. Sevilla, EEHA, 1985.

Serrano Mangas, F.: Naufragios y rescates en el tráfico indiano durante el siglo XVII. Lima, 1991.

Tapias Herrero, E.: «El sueño del almirante Pes: el traslado de la Casa de Contratación a Cádiz en 1717», Pliegos de la Academia, 20, 2014, pp. 9-24.

Tapias Herrero, E.: «Colbert y Patiño: Dos colosos en las marinas borbónicas», Revista de Historia Naval, 134, 2016, pp. 9-30.

Tapias Herrero, E.: El almirante López Pintado (1677-1745). El duro camino del éxito en la Carrera de Indias. Sevilla, Editorial Universidad de Sevilla, 2017.

VALDEZ-Bubnov, I.: «The politics of Spanish Shipbuilding Legislation, 1607-1728», International Journal of Maritime History, XXI:2, 2009, pp. 75-102.

Veitia Linaje, J.: Norte de la Contratación de las Indias Occidentales. Madrid, 1981.

Velázquez Gaztelu, J. P.: Estado marítimo de Sanlúcar de Barrameda. Sanlúcar, 1998.

Walker, G. J.: Política española y comercio colonial 1700-1789. Barcelona, Ariel, 1979.

Ediciones Universidad de Salamanca / 